\title{
Psycholinguistic Perspectives on Comprehension in SLA
}

\author{
Parisa Naseri Karimvand \\ Payam-e-noor University, Iran \\ Email: prsnaseri@yahoo.com
}

\begin{abstract}
There are many interesting areas of investigation in the psychology of second language acquisition (SLA). One of these interesting areas is study of the psycholinguistic processes and perspectives relevant to reading and listening comprehension. Comprehension of any given text or speech, in SLA, is based on much more than simple decoding. Familiarity with cultural nuance, structure of the language, vocabulary development, background knowledge about the setting and/or topic, and attitude toward the text are some of the most common factors involved in the process of comprehension by English learners. Listening and reading have many things in common. Both listening and reading are a form of language comprehension in which one is trying to get some meaning from the language. Understanding how comprehension works can have huge implications in language pedagogy, testing and research. So, this paper aims at providing a general overview about reading and listening comprehension in SLA, based on the literature review. In this regard, first a brief introduction to SLA Psycholinguistic theories and their pros and cons is presented. Later, the study is narrowed down to the very processes involved in comprehension of reading and listening, in particular. At the end, a short discussion about the brain's language areas active in the process of comprehension is ensued.
\end{abstract}

Index Terms - listening comprehension, psycholinguistic, reading comprehension, SLA

\section{INTRODUCTION}

Prior to the time of Chomsky, "little was known about the process of second language acquisition, and thus (traditional approaches) were grounded in the linguistic, psychological, and pedagogical theories of their day." Nowadays there are major theories of language acquisition and language learning which many psycholinguists and applied linguistics are familiar with: Behaviorism, Neo-behaviorism, Cognitivism, and Humanism. Currently, there are hot debates about the last two theories. What follows is the brief introduction to the famous psycholinguistic approaches and hypothesis in SLA.

\section{FAmous Psycholinguistic APPROACHES To SeCOND LANGUAGE LEARNING (SLL)}

Psycholinguistic approaches to SLL, mainly interactionists, conceive language learning (LL) as a cognitive and individual process in which knowledge is constructed as the learner is (1) exposed to comprehensible input (Krashen, 1985), (2) is given opportunities to both, negotiate meaning (Gass, 1997) and (3) receive negative feedback (Long, 1996). Major pycholinguistic approaches to SLL tend to agree that a learner needs to be exposed to input. However, there is no agreement on the type of input needed and much less, how such input is processed in order to become acquired (Gass, 1997).

One of the less accepted theories of input is Krashen's input hypothesis (1985). This theory predicts the likelihood for a learner to acquire a language when he/she is exposed to comprehensible input. Thus, to increase the chances for input comprehension, input should be just one step beyond the learner's current stage of linguistic competence.

Although numerous SLA scholars have favored and/or contradicted Krashen's model of SLA based on arguments such as flaws in the theory and lack of empirical support data (see Gass, 1997), Long (1996) revisited Krashen's input hypothesis to explore forms in which input comprehensibility can be increased and proposed the interaction hypothesis (IH). The interaction hypothesis asserts that besides the input the learner is exposed to, manipulation of such input through interaction is what forms the basis for language development. According to Long (1996) input comprehensibility increases as learners interact and use different type of interactional modifications (comprehension checks, confirmation checks, and clarification requests) to overcome communication breakdowns. Long's initial work was criticized by SLA scholars, mostly outside of the interactionist areas, who believed that he did not provide clear-cut definitions and proper examples for each type of modification. The point is that learners need to receive negative feedback while in IH-based hypothesis, emphasis was initially placed on the task and learners' variables that seem to favor SLLs.

Another famous psycholinguistic approach to SLA is Socio-cultural approach. Studies in SLA from the socio-cultural perspective are based on the work of Vigotsky (1978) in which three main themes are identified: mediation, social learning and genetic analysis. Mediation describes how tools and signs transform human action and influence the way people perceive the world. In this sense, language is perceived as the most powerful mediational tool because through 
the use of words different things can be accomplished. Social learning is explained by the Zone of Proximal Development (ZPD) metaphor. The ZPD is defined as "the distance between the actual developmental level as determined by independent problem solving and the level of potential development as determined through problem solving under adult guidance, or in collaboration with more capable peers" (as cited in Lantolf and Thorne, 2006). The last theme identified in the Vigotskian framework, genetic analysis, under scores the importance of looking for causes, genesis or origins and histories to understand different aspects of mental functioning. Language development resulting from the interaction of expert-novice (also known as the scaffolding metaphor) has also been an interest of research in the socio-cultural theory. Scaffolding refers to the assistance provided by a more capable learner to his interlocutor and that enables him to do activities he would not have been able to do without such assistance (Lantolf \& Thorne, 2006).

In the state of art review of socio-cultural theory and L2, Lantolf (2006) suggests that the union of socio-cultural theory and cognitive linguistics may help to better explain how language learners internalize and develop the capacity to develop conceptual and associated linguistic knowledge. He also suggests that further research could investigate if there is a connection between the linguistic features of the private speech of L2 learners and the linguistic features of interaction occurring between L2 speakers.

During the recent years, the new attempts of some cognitivists and socio-cultural researchers have opened up new methodologies and collaborate in SLA comprehension studies. It has stimulated the field and complete insights of L2 comprehension.

Now that principle theories in SLA has just introduced, in the rest of the paper the writer, particularly, deals with reviewing the primary psycholinguistic processes involved in SLA comprehension. In this regard, first general points about speech comprehension processes are explained. Then, phenomena common to reading and listening comprehension are clarified. Furthermore, phenomena specific to the comprehension of the spoken language is presented. Finally, famous language areas involved in SLA comprehension is explained.

\section{SPEECH COMPREHENSION PROCESSES IN SLA}

Study of speech comprehension processes is important in various ways. For instance, it has direct relationship with recognition of psycholinguistic processes of output and why comprehensible input is not enough to drive the learners' IL development. Decades of research in psycholinguistics give us some useful insights in this regard. Some of the major characteristics of human speech comprehension processes can be briefly summarized as follows (for detailed discussion, see Fender, 2001):

- Comprehension processes rely on three types of information: linguistic input, contextual information, and the recipient's linguistic and other general knowledge of the world, including semantic and pragmatic knowledge.

- Comprehension is differentially affected by the linguistic devices used in the sentence. The use of linguistic cues in comprehension processes is referred to as bottom-up processing.

- Comprehension is differentially affected by the existence, type and the amount of contextual clues provided. People tend to seek contextual consistency in comprehending speech.

- Comprehension is differentially affected by the general world knowledge possessed by the recipients. The use of contextual clues and world knowledge in comprehension processes is referred to as top-down processing.

- Comprehension is selective because humans possess limited processing capacities.

These characteristics of the human speech comprehension system suggest that highly complex processes underlie speech comprehension. People do not rely on only one general knowledge source to understand speech, but they use various resources available to them, using both top-down and bottom-up approaches, to arrive at the comprehension of the input messages.

In fact, some researchers argue that even adult native listeners/readers do not use the two general approaches of syntactic and semantic processing equally in comprehending speech. Clark and Clark (1977), for example, argue that syntactic information may be circumvented in comprehension processes in listening and reading because people can usually make good guesses about what is to be comprehended even before they hear/read anything. In reading research, Stanovich's (1980) interactive-compensatory model of reading posits that the reader is not merely a passive recipient of the printed information, but as an active subject in the whole process who uses all the knowledge resources available to $\mathrm{him} /$ her. What is particularly interesting about this model is not just the interactive nature of the reading processes, but its compensatory mechanisms. If there is a deficiency in any particular process (e.g., weak syntactic knowledge), other processes (e.g., higher-order knowledge structures, such as contextual or general world information that the reader has access to) can compensate for the weak knowledge source. Thus, with information provided simultaneously from several knowledge sources, a deficit in any knowledge results in a heavier reliance on other knowledge sources.

In first language acquisition literature, it has been claimed that children typically rely on general world knowledge for comprehension, such as their general knowledge about the instigators of actions which are typically animate, probable relations between nouns in a sentence, and the knowledge of the usual routine in particular circumstances to decide how to act. In SLA, as well, restricted L2 knowledge of the learners makes them rely on certain strategies more than others. Skehan (1998), for example, argues that L2 learners use a variety of strategies of comprehension that may obviate careful attention to form. Skehan points out that L2 learners are those who have 'schematic knowledge' (i.e., factual and sociocultural background knowledge and discoursal procedural knowledge), but have limited 'systemic 
knowledge' (i.e., syntactic, semantic, and morphological knowledge). Such learners may be likely to exploit their schematic knowledge to overcome limitations in their systemic knowledge. This can lead to a reduced chance for the engagement of the IL system.

To summarize, although the resourceful nature of the comprehension system is highly useful in making L2 comprehension possible, this also implies that L2 learners can attain an adequate level of comprehension without necessarily focusing on many formal features in the input. This can lead to a reduction in the amount of intake that can be used for final integration in the developing system.

Particularly speaking from psycholinguistic perspective, in language comprehension and speech perception many factors are at work. First of all, we have to identify single sounds that make up recognizable words, then retrieve from our mental lexicon the meaning of these words, which in their turn form meaningful sentences in a given situation. If split up into these 'logical' steps, however, the process of speech perception is inconceivable. Strictly speaking, our short-term memory is not able to store that much information at once. To give an example: If we had to decode every single sound when listening to somebody, we would already have forgotten the first sound of a long word once we had identified the last one (let alone the word boundaries). The same holds true for the decoding of the smallest text units, i.e. letters. This is why we can only explain the phenomenon of speech perception if we take the following assumptions as a basis:

a) As experienced listeners we have at our disposal a large amount of previous information as well as specific expectations as to what we are about to hear. Consequently, we just have to check whether our expectations are confirmed by what we have actually heard. To put it crudely, in many cases we do not necessarily hear what our interlocutor says but what we expect to hear. This is the reason why many nonsense errors or mispronounced words in speech go unnoticed or are easily forgotten, whereas meaningful errors can often be remembered.

b) Apart from this, we are constantly building up new hypotheses on what will come next while listening. Similarly to the role of our pre-expectations, we compare these hypotheses with what we have just heard. Since we often know, or at least think we know, what our interlocutors are about to say next, we sometimes tend to interrupt them or add to their utterance.

c) Finally, every word that has been recognized and every sentence that has been understood are instantly transferred to different, 'higher' forms of representation in our memory and are integrated into our dynamic horizon of expectations and stock of knowledge. This means that we rarely store individual words or the wording of sentences but rather the rough meaning of what has been said. As a result, our memory is rather unreliable as far as details are concerned, and we often add things to our stock of knowledge that have never been actually said. The processing of words, i.e. their location and the attribution of meaning within the networks of the mental lexicon, is usually done within milliseconds. However, the exact strategies, which even allow for an efficient categorization of non-words, appear to be individual and thus are not generalisable. What we can record in this regard is the following: Words are primarily, but not necessarily, stored as wholes. There is also the possibility of splitting them up if required (e.g. into morphemes). Further, words can be connected within the mind via their (initial and final) sounds and rhythm as well as via their syntactic relations. What is more, semantic networks may very probably be activated, including relations such as synonymy, antonymy, hyperonymy, hyponymy etc.

Mental processes with respect to language may be neither definable nor common to all. However, different psycholinguistic models exist that try to elucidate word recognition. On the one hand, words are said to be processed linearly, i.e. one after the other, while frequent words are recognized more easily and thus faster. On the other hand, and this might be the option which comes closer to reality, words are said to be processed in parallel. In the latter view, possible meanings are weighed against each other, resulting in an interpretation that suits the context best. In fact, we are linguistic puzzle-solvers from early childhood on. The storage of linguistic structures and functions in the mind, i.e. knowledge, is directly linked to comprehension.

\section{PHENOMENA COMMON TO READING AND LISTENING COMPREHENSION}

Comprehension of written and spoken language can be difficult, in part, because it is not always easy to identify the constituents (phrases) of a sentence and the ways in which they relate to one another. The place of a particular constituent within the grammatical structure may be temporarily or permanently ambiguous. Studies of how people resolve grammatical ambiguities, like studies of how they resolve lexical ambiguities, have provided insights into the processes of language comprehension. Clark (1997) found that readers' eyes fixated for longer than usual on the verb which disambiguates the sentence. Following Bever (1970), Clark described their readers as being led down a garden path. Readers are led down the garden path, Clark (1997) claimed, because the direct object analysis is structurally simpler than the other possible analysis. These researchers proposed a principle, minimal attachment, which defined "structurally simpler," and they claimed that structural simplicity guides all initial analyses. In this view, the sentence processor constructs a single analysis of a sentence and attempts to interpret it. The first analysis is the one that requires the fewest applications of grammatical rules to attach each incoming word into the structure being built; it is the automatic consequence of an effort to get some analysis constructed as soon as possible. Many researchers have tested and confirmed the minimal attachment principle for a variety of sentence types.

Minimal attachment is not the only principle that has been proposed as governing how readers and listeners use 
grammatical knowledge in parsing. Another principle that has received substantial support is late closure. Clark (1997) provided some early support for this principle by showing disruption on the phrase seems like in Since Jay always jogs a mile seems like a very short distance to him. Here, a mile is first taken to be the direct object of jogs because the processor tries to relate it to the phrase currently being processed. Reading is disrupted when a mile must be reanalyzed as the subject of seems.

Another principle is some version of prefer argument (Abney, 1989). Grammars often distinguish between arguments and adjuncts. An argument is a phrase whose relation to a verb or other argument assigner is lexically specified; an adjunct is related to what it modifies in a less specific fashion. With the sentence Joe expressed his interest in the car, the prefer argument principle predicts that a reader will attach in the car to the noun interest rather than to the verb express, even though the latter analysis is structurally simpler and preferred according to minimal attachment. In the car is an argument of interest (the nature of its relation to interest is specified by the word interest) but an adjunct of express (it states the location of the action just as it would for any action). There is substantial evidence that the argument analysis is preferred in the end (Gass, 1997). However, some evidence suggests a brief initial preference for the minimal attachment analysis. Long-distance dependencies, like ambiguities, can cause problems in the parsing of language. Language gains much of its expressive power from its recursive properties: Sentences can be placed inside sentences, without limit. This means that related phrases can be distant from one another. Many linguists describe constructions like Whom did you see $\mathrm{t}$ at the zoo and The girl $\mathrm{I}$ saw $\mathrm{t}$ at the zoo was my sister as having an empty element, a trace (symbolized by t), in the position where the moved element (whom and the girl) must be interpreted.

Psycholinguists who have adopted this analysis ask how the sentence processor discovers the relation between the moved element (or filler) and the trace (or gap). One possibility suggested is that the processor might delay filler-gap assignment as long as possible. However, there is evidence that the processor actually identifies the gap as soon as possible, an active filler strategy (Frazier, 1987b).

The active filler strategy is closely related to minimal attachment, for both strategies attempt to find some grammatical analysis of a sentence as soon as possible. But the active filler strategy may not be the whole story. Pickering and Barry (1991) proposed what the latter called a direct assignment strategy, according to which a filler is semantically interpreted as soon as a reader or listener encounters the verb to which it is related, without waiting for the gap position. Evidence for this strategy comes from a study in which Boland et al. presented sentences word by word, asking readers to indicate when and if a sentence became unacceptable. An implausible sentence like Which public library did John contribute some cheap liquor to t last week tended to be rejected right on the word liquor, before the position of the gap.

Most of the phenomena discussed so far show that preferences for certain structural relations play an important role in sentence comprehension. However, as syntactic theory has shifted away from describing particular structural configurations and toward specifying lexical information that constrains possible grammatical relations, many psycholinguists have proposed that the human sentence processor is primarily guided by information about specific words that is stored in the lexicon. The research on comprehenders' preference for arguments discussed earlier is one example of this.

Given the wide variety of factors that seem to affect sentence comprehension, some psycholinguists have developed lexicalist, constraint-based theories of sentence processing (Long, 2007). These theories, which are described and sometimes implemented in connectionist terms, assume that multiple possible interpretations of a sentence are available to the processor. Each possible interpretation receives activation (or inhibition) from some knowledge sources, as well as (generally) being inhibited by the other interpretations. Competition among the interpretations eventually results in the dominance of a single one. Increased competition is responsible for the effects that the theories discussed earlier have attributed to the need to revise an analysis. Constraint-based theories can accommodate influences of specific lexical information, context, verb category, and many other factors, and they have encouraged the search for additional influences. However, they may not be the final word on sentence processing. These theories correctly predict that a variety of factors can reduce or eliminate garden-path effects when a temporarily-ambiguous sentence is resolved in favor of an analysis that is not normally preferred (e.g., non-minimal attachment). But the constraint-based theories also predict that these factors will create garden paths when the sentence is resolved in favor of its normally-preferred analysis. This may not always be the case (Binder, Duffy, \& Rayner, 2001).

Competitive constraint-based theories, like other connectionist theories, grant a major role to frequency. Frequent constructions should be more readily activated by appropriate sources of information than less common constructions are. Supporting this view, readers understand sentences like The award accepted by the man was very impressive more readily when the first verb is frequently used as a passive participle, as accept is, than when the verb is not frequently used as a passive particle, as with entertain (Trueswell, 1996). Competitive constraint-based theories have also emphasized discourse and situational context as constraints on sentence comprehension. Many researches described how quickly listeners integrate grammatical and situational knowledge in understanding a sentence.

Much research on text comprehension in SLA has been guided by the work of Kintsch (1978), who has proposed a series of models of the process by which the propositions that make up the semantic interpretations of individual sentences are integrated into such larger structures. His model is showed below. It describe ways in which readers could abstract the main threads of a discourse and infer missing connections, constrained by limitations of short-term memory 
and guided by how arguments overlap across propositions and by linguistic cues signaled by the text.

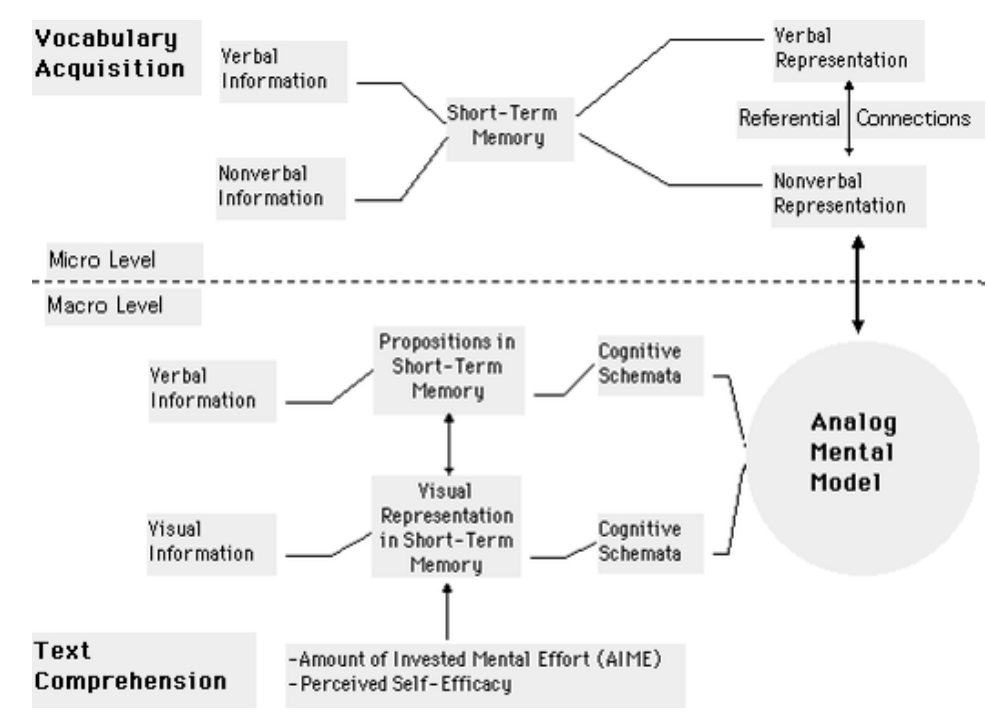

\section{PHENOMENA SPECIFIC TO THE COMPREHENSION OF SPOKEN LANGUAGE}

The theories and phenomena that we have discussed so far apply to comprehension of both spoken language and written language. One challenge that is specific to listening comes from the evanescent nature of speech. People can not re-listen to what they have just heard in the way that readers can move their eyes back in the text. However, the fact that humans are adapted through evolution to process auditory, not written language suggests that this may not be such a problem. Auditory sensory memory can hold information for up to several seconds (Cowan, 1984), and so language that is heard may in fact persist for longer than language that is read, permitting effective revision. In addition, auditory structure may facilitate short-term memory for spoken language. Imposing a rhythm on the items in a to-be-remembered list can help people remember them and prosody may aid memory for sentences as well (Speer, 1993). Prosody may also guide the parsing and interpretation of utterances. For example, prosody can help resolve lexical and syntactic ambiguities, it can signal the importance, novelty, and contrastive value of phrases, and it can relate newly-heard information to the prior discourse. If readers translate visually presented sentences into a phonological form, complete with prosody, these benefits may extend to reading (Bader, 1998).

Consider how prosody can permit listeners to avoid the kinds of garden paths that have been observed in reading (Clark, 1997). Several researchers have demonstrated that prosody can disambiguate utterances. In particular, an intonation phrase boundary (marked by pausing, lengthening, and tonal movement) can signal the listener that a syntactic phrase is ending. The relevant prosodic property does not seem to be simply the occurrence of a local cue, such as an intonational phrase break. Rather, the effectiveness of a prosodic boundary seems to depend on its relation to certain other boundaries (Carlson, 2001), even the global prosodic representation of a sentence.

\section{CRITICAL AREAS IN LANGUAGE COMPREHENSION}

The left temporal region has been implicated in several studies of sentence comprehension in both the auditory and the visual modalities (Long, 2007), and as expected, this region showed considerable activation. Although one cannot tell from the fMRI data what precise set of processes underlies the temporal region activation, this region's sensitivity to linguistic difficulty of both types is consistent with different SLA hypotheses discussed above, namely that the area plays a role in activating and perhaps coordinating the systems that support linguistic comprehension and interpretation. The left opercular region, the posterior part of Broca's area, has been implicated in numerous sentence comprehension studies. Comprehension of sentences and discourse Important as word recognition is, understanding language requires far more than adding the meanings of the individual words together. We must combine the meanings in ways that honor the grammar of the language and that are sensitive to the possibility that language is being used in a metaphoric or non-literal manner (see Cacciari \& Glucksberg, 1994). Psycholinguists have addressed the phenomena of sentence comprehension in different ways. Some theorists have focused on the fact that the sentence comprehension system continually creates novel representations of novel messages, following the constraints of a language's grammar, and does so with remarkable speed. Others have emphasized that the comprehension system is sensitive to a vast range of information, including grammatical, lexical, and contextual, as well as knowledge of the speaker/writer and of the world in general. Theorists in the former group (Clark, 1997) have constructed modular, serial models that describe how the processor quickly constructs one or more representations of a sentence based on a restricted range of information that is guaranteed to be relevant to its interpretation, primarily grammatical information. Any such representation is then 
quickly interpreted and evaluated, using the full range of information that might be relevant. Theorists in the latter group (Long, 2007) have constructed parallel models, often of a connectionist nature, describing how the processor uses all relevant information to quickly evaluate the full range of possible interpretations of a sentence. Neither of the two approaches just described provides a full account of how the sentence processing mechanism works. Modular models, by and large, do not adequately deal with how interpretation occurs, how the full range of information relevant to interpretation is integrated, or how the initial representation is revised when necessary. Parallel models, for the most part, do not adequately deal with how the processor constructs or activates the various interpretations whose competitive evaluation they describe. However, both approaches have motivated bodies of research that have advanced our knowledge of language comprehension, and new models are being developed that have the promise of overcoming the limitations of the models that have guided research in the past.

\section{ACKNOWLEDGEMENT}

I would like to appreciate my parents for all their support and kindness generally during my educational life and particularly in developing this research study.

\section{REFERENCES}

[1] Abney, S. (1989). A computational model of human parsing. Journal of Psycholinguistic Research, 18, 129-144.

[2] Bader, M. (1998). Prosodic influences on reading syntactically ambiguous sentences. In J. Fodor \& F. Ferreira (Eds.), Reanalysis in sentence processing (pp. 1-46). Dordrecht: Kluwer.

[3] Bever, T. G. (1970). The cognitive basis for linguistic structures. In J. R. Hayes (Ed.), Cognition and the development of language (pp. 279-352). New York: Wiley.

[4] Cacciari, C., \& Glucksberg, S. (1994). Understanding figurative language. In M.A. Gernsbacher (Ed.), Handbook of psycholinguistics (pp. 447-477). San Diego, CA: Academic press.

[5] Carlson, K., Clifton, C., Jr., \& Frazier, L. (2001). Prosodic boundaries in adjunct attachment. Journal of Memory and Language, $45,58-81$.

[6] Clark, H.H. (1997). Using language. Cambridge: University Press.

[7] Cowan, N. (1984). On short and long auditory stores. Psychological Bulletin, 96, 341- 370.

[8] Fender, M.J. (2001). A review of L1 and L2/ESL word integration skills and the nature of L2/ESL word integration development involved in lower-level text processing. Language Learning, 51, 319-396.

[9] Gass, S. M. (1997). Input, Interaction, and the Second Language Learner. Mahwah, NJ: Lawrence Erlbaum.

[10] Kintsch, W. (1987). The use of knowledge in discourse processing. Psychological Review, 95, 163-182.

[11] Krashen, S. D. (1985). The Input Hypothesis: Issues and Implications: Longman.

[12] Lantolf, J. P. (2000). Introducing sociocultural theory. Sociocultural theory and second language learning, 1-26.

[13] Lantolf, J. P., \& Thorne, S. L. (2006). Sociocultural theory and the genesis of second language development: Oxford University Press.

[14] Long, M. H. (1996). Authenticity and learning potential in L2 classroom discourse. In Jacobs, G. M. (ed.), Language classrooms of tomorrow: Issues and responses, 148-69.

[15] Long, M. H. (1997). Construct Validity in SLA Research: A Response to Firth and Wagner. The Modern Language Journal, 81(3), 318-323.

[16] Long, M. (2007). Problems in SLA: Mahwah, NJ L. Erlbaum Associates.

[17] Mackey, A., \& Gass, S. (2006). Introduction. Studies in Second Language Acquisition, 28(02), 169-178.

[18] Pickering, M.J., \& Barry, G. (1991). Sentence processing without empty categories. Language and Cognitive Processes, 6 , 229-259.

[19] Skehan. P. (1998). A cognitive approach to language learning. ELT Journal, 6, 398-399.

[20] Speer, S.R., Crowder, R.G., \& Thomas, L.M. (1993). Prosodic structure and sentence ecognition. Journal of Memory and Language, 32, 336-358.

[21] Stanovich, K. E. (1980). Toward an interactive-compensatory model of individual differences in the development of reading fluency. Reading Research Quarterly, 16, 32-71.

[22] Trueswell, J.C. (1996). The role of lexical frequency in syntactic ambiguity resolution. Journal of Memory and Language, 35, 566-585.

[23] Vygotsky, L. (1978). Interaction between Learning and Development (pp. 79-91). In Mind in Society. (Trans. M. Cole). Cambridge, MA: Harvard University Press.

Parisa Naseri Karimvand is a Ph. D candidate in TEFL. She teaches technical courses to BA students in universities. She presented technical papers in her areas of interest in national and international conferences. 